\title{
Impacto do Tratamento Antineoplásico na Microbiota da Cavidade Oral e Orofaríngea de Pacientes Acometidos pelo Câncer de Cabeça e Pescoço: Revisão Sistemática
}

doi: https://doi.org/10.32635/2176-9745.RBC.2022v68n1.1581

\author{
Impact of Antineoplastic Treatment on Oral Cavity and Oropharyngeal Microbiota of Head and Neck Cancer Patients: \\ Systematic Review \\ Impacto del Tratamiento Antineoplástico en la Microbiota Oral y Orofaríngea de Pacientes Afectados por el Cáncer de \\ Cabeza y Cuello: Revisión Sistemática
}

Iran Alves da Silva'; Larissa Karine Barbosa²; Diego Belmiro do Nascimento Santos³; Sibele Ribeiro de Oliveira4; Cláudia Cristina Brainer de Oliveira Mota5; Adrya Lúcia Peres ${ }^{6}$

\section{RESUMO}

Introduçáo: As cavidades oral e orofaríngea apresentam uma grande diversidade de micro-organismos que se encontram normalmente em homeostase com outros micro-organismos e o próprio hospedeiro, contudo, pacientes com câncer de cabeça e pescoço submetidos ao tratamento oncológico podem desencadear modificaçóes fisiológicas nos seus organismos, assim como impactos na sua microbiota residente. Objetivo: Revisar sistematicamente os estudos sobre o impacto provocado pelo tratamento antineoplásico sobre a microbiota oral e orofaríngea em pacientes com câncer de cabeça e pescoço. Método: Revisão sistemática, realizada entre abril e junho de 2020. Busca nas bases de dados Biblioteca Virtual em Saúde, Google Acadêmico, PubMed e ScienceDirect. Utilizaram-se os descritores "head and neck neoplasms", "mouth neoplasms" e "microbiota" em inglês; e "neoplasias de cabeça e pescoço", "neoplasias bucais" e "microbiota" em português. Foram selecionados artigos originais e disponíveis na íntegra, publicados na última década (2010 a 2020), nos idiomas português e inglês. Resultados: Foram incluídos oito artigos nesta revisão. Assim, a maioria dos estudos apresentou alterações na quantidade de micro-organismos residentes ou invasão de bactérias exógenas nos pacientes submetidos ao tratamento antineoplásico; o descontrole da homeostase da microbiota desencadeou processos cariogênicos e inflamatórios na mucosa. Conclusáo: As alteraçóes no microbioma da cavidade oral e orofaríngea advindas do tratamento antineoplásico podem ser fatores de predisposição a efeitos adversos no indivíduo, como desenvolvimento de cárie e mucosite oral.

Palavras-chave: neoplasias bucais; neoplasias de cabeça e pescoço; microbiota; antineoplásicos.

\section{ABSTRACT}

Introduction: A great diversity of microorganisms are found in the oral and oropharyngeal cavities, which are normally in homeostasis with other microorganisms and the host itself. Patients with head and neck cancer undergoing cancer treatment may trigger physiological changes in their bodies and impact in the resident microbiota. Objective: Systematically review studies on the impact of antineoplastic treatment on oral and oropharyngeal microbiota in patients with head and neck cancer. Method: Systematic review carried out between April and June 2020. Articles were searched in the Virtual Health Library, Google Scholar, PubMed and ScienceDirect databases in English, utilizing the descriptors "head and neck neoplasms", "mouth neoplasms" and "microbiota" and "neoplasias de cabeça e pescoço", "neoplasias bucais" and "microbiota" in Portuguese. Original articles available in full, published in the last decade (2010 to 2020), in Portuguese and English were selected. Results: 8 articles were included in this review. Most of studies have shown quantitative changes in resident microorganisms or invasion of exogenous bacteria in patients in antineoplastic treatment; uncontrolled microbiota homeostasis triggered cariogenic and inflammatory processes in the mucosa. Conclusion: Changes in the microbiome of the oral cavity and oropharyngeal resulting from antineoplastic treatment may be predisposing factors for adverse effects as the development of caries and oral mucositis.

Key words: mouth neoplasms; head and neck neoplasms; microbiota; antineoplastic agents.

\section{RESUMEN}

Introducción: Las cavidades bucal y orofaríngea presentan una gran diversidad de microorganismos que normalmente se encuentran en homeostasis con otros microorganismos y su propio hospedador, sin embargo, los pacientes con cáncer de cabeza y cuello sometidos a tratamiento contra el cáncer pueden desencadenar cambios fisiológicos en tu cuerpo, así como también impactos en su microbiota residente. Objetivo: Revisar sistemáticamente los estudios sobre el impacto del tratamiento antineoplásico en la microbiota oral y orofaríngea en pacientes con cáncer de cabeza y cuello. Método: Revisión sistemática realizada entre abril y junio de 2020. Se buscaron artículos en las bases de datos de la Biblioteca Virtual en Salud, Google Scholar, PubMed y ScienceDirect. Se utilizaron los descriptores "head and neck neoplasms", "mouth neoplasms" and "microbiota" en inglés y "neoplasias de cabeça e pescoço", "neoplasias bucais" e "microbiota" en portugués. Incluyeron artículos originales y disponibles en su totalidad, publicados en la última década (2010 a 2020), en portugués e inglés. Resultados: En esta revisión se incluyeron ocho artículos. Así, la mayoría de los estudios han mostrado cambios en el número de microorganismos residentes o invasión de bacterias exógenas en pacientes sometidos a tratamiento antineoplásico, la homeostasis de la microbiota sin controle desencadena procesos cariogénicos e inflamatorios en la mucoso. Conclusión: Los cambios en el microbioma de la cavidad oral y orofaríngea por el tratamiento antineoplásico pueden ser factores predisponentes a los efectos adversos en el individuo, como el desarrollo de caries y mucositis oral. Palabras clave: neoplasias de la boca; neoplasias de cabeza y cuello; microbiota; antineoplásicos.

\footnotetext{
${ }^{1-6}$ Centro Universitário Tabosa de Almeida. Associação Caruaruense de Ensino Superior e Técnico (Asces-Unita). Caruaru (PE), Brasil.

'E-mail: iranalvesdasilva0@gmail.com. Orcid iD: https://orcid.org/0000-0002-7295-3869

2E-mail: 2017220029@app.asces.edu.br. Orcid iD: https://orcid.org/0000-0002-8312-8549

${ }^{3}$ E-mail: diegobelmiro@outlook.com. Orcid iD: https://orcid.org/0000-0002-0109-6863

${ }^{4} \mathrm{E}$-mail: sibeleribeiro@asces.edu.br. Orcid iD: https://orcid.org/0000-0001-8211-7357

${ }^{5}$ E-mail: claudiabmota@gmail.com. Orcid iD: https://orcid.org/0000-0002-7909-5908

${ }^{6}$ E-mail: adryaperes@asces.edu.br. Orcid iD: https://orcid.org/0000-0003-4892-5486

Endereço para correspondência: Iran Alves da Silva. Rua José Joaquim de Araújo, 162 - Manoel Lucas. Santa Cruz do Capibaribe (PE), Brasil. CEP 55195-039. E-mail: iranalvesdasilva0@gmail.com
} 


\section{INTRODUÇÃO}

Os tumores malignos de lábios, cavidade oral, faringe, laringe, cavidade nasal e tireoide são agrupados como cânceres de cabeça e pescoço. Os principais sítios anatômicos acometidos nesse grupo de neoplasias constituem a cavidade oral (mucosa bucal, gengiva, palato duro, lingual e assoalho de língua); a faringe (orofaringe, nasofaringe e hipofaringe); a cavidade nasal e os seios paranasais; a laringe glótica, supraglótica e glândulas. Cerca de $40 \%$ das lesôes ocorrem na cavidade oral, $15 \%$ na faringe, $25 \%$ na laringe e os $20 \%$ restantes estáo distribuídos nos demais sítios ${ }^{1}$. O número de casos novos de câncer da cavidade oral esperados para o Brasil, para cada ano do triênio 2020-2022, será de 11.200 casos em homens e de 4.010 em mulheres ${ }^{2}$.

O câncer de cabeça e pescoço frequentemente é diagnosticado em estágios já avançados ${ }^{3}$. Desse modo, a demora para a confirmação diagnóstica e a definição do tratamento acabam levando a uma terapêutica mais agressiva e, consequentemente, a um maior número de reaçôes adversas como consequência do tratamento ${ }^{4}$. A radioterapia é geralmente a terapia de primeira escolha, sendo direcionada à região de cabeça e pescoço, podendo desencadear efeitos adversos como mucosite, xerostomia, disgeusia, odinofagia e infecçôes 5 .

Nas regiōes da cavidade oral e orofaríngea, a presença de micro-organismos ultrapassa mais de 700 espécies; ainda se estima que várias espécies não foram catalogadas taxonomicamente, tendo em vista que a semelhança do seu material genético com espécies já registradas é um fator que impossibilita a total descrição do bioma microbiano ${ }^{6}$. Os filos de bactérias já identificados e com maior prevalência são Firmicutes, Bacteroidetes, Proteobacteria, Actinobacteria $e$ Fusobacteria. Enquanto os gêneros de bactérias de maior predominância correspondem a Streptococcus, Actinomyces, Veillonella, Fusobacterium, Porphyromonas, Prevotella, Treponema, Neisseria, Haemophilis, Lactobacillus, Capnocytophaga, Eikenella, Leptotrichia, Peptostreptococcus, Staphylococcus e Propionibacterium ${ }^{7,8}$.

Dentro dos gêneros citados, o Streptococcus é mais frequente, sendo uma bactéria com forma de cocos Gram- positivas. Mesmo fazendo parte da microbiota residente, algumas espécies como Streptococcus mutans em condiçóes favoráveis à sua proliferação podem causar cárie dentária, já que são capazes de fermentar uma grande variedade de açúcares?. Além disso, bactérias como Enterococcus faecalis, Enterococcus faecium e Escherichia coli, comuns no trato gastrointestinal inferior, podem acabar colonizando a cavidade oral de forma acidental, seja por transmissão de água e alimentos contaminados, objetos infectados ou até mesmo contato com as fezes contaminadas; podendo desencadear processos infecciosos ${ }^{10,11}$.
Fungos se encontram em um quantitativo menor, porém estabelecem um papel primordial na manutenção do equilíbrio da microbiota oral, podendo ser encontrados os dos gêneros Candida, Cladosporium, Aureobasidium, Saccharomyces, Aspergillus, Fusarium e Cryptococcus. O gênero Candida, principalmente a espécie Candida albicans, pode ser um fator de risco para infecçóes denominadas de candidíase, principalmente em pacientes imunocomprometidos ${ }^{12}$.

Sabe-se que, em condiçôes saudáveis, a microbiota se relaciona a um estado de homeostase com o hospedeiro, semelhante ao que ocorre com as outras interaçôes entre os micro-organismos em diferentes partes do corpo humano ${ }^{13}$. Esses micro-organismos desempenharam um papel vital na construção de um ambiente ideal para a sua sobrevivência, melhor absorção de nutrientes, interação com outras espécies por meio da comunicação microbiana, regulando as taxas de crescimento microbiano e até mesmo protegendo o hospedeiro de micro-organismos exógenos com potencial patogênico ${ }^{14}$. Entre os fatores que auxiliam na relaçáo entre as interaçôes envolvidas por micro-organismos e seu habitat, destacam-se a temperatura, $\mathrm{pH}$, presença de oxigênio (potencial oxidação-redução), nutrientes (endógenos e exógenos) e o próprio sistema de defesa do hospedeiro ${ }^{15}$. Todos esses fatores são imprescindíveis na microbiota no processo saúde-doença, pois modulam a colonizaçáo por determinados micro-organismos, os quais serão capazes de sobreviver e se proliferar no ambiente e, assim, estabelecer a microbiota residente ${ }^{16}$.

Ainda há paradigmas a respeito dos efeitos do tratamento antineoplásico em relaçáo aos micro-organismos que habitam a cavidade oral e orofaríngea. Pacientes em terapia antineoplásica acabam apresentando muitas vezes o sistema imunológico comprometido, além de serem acometidos pela redução do fluxo salivar e pela possibilidade de mucosite, que acaba tornando mais suscetível a quebra da homeostase da microbiota, criando um habitat mais propício a infecçóes, seja de micro-organismos residentes que proliferam de maneira incontrolável ou pela invasão e fixação de micro-organismos exógenos patogênicos. Tal problemática pode provocar uma piora no quadro clínico do paciente e até contribuir em suspensão do tratamento antineoplásico ${ }^{17}$. Nesse contexto, micro-organismos, principalmente bactérias, podem trazer consigo multirresistência a antibióticos e alto percentual de virulência, agravando o processo infeccioso até gerar um quadro de sepse. $\mathrm{O}$ Instituto Latino-Americano de Sepse (ILAS) ${ }^{18}$ estima que 400 mil casos de sepse são diagnosticados por ano no Brasil, provocando aproximadamente a morte de $240 \mathrm{mil}$ indivíduos. A taxa de mortalidade no país é de $65 \%$ dos 
casos, $25 \%$ maior do que a média mundial (30\%-40\%). Ainda de acordo com o ILAS, $25 \%$ da ocupação de leitos nas Unidades de Terapia Intensiva (UTI) ocorrem pela sepse, sendo a principal causa de morte nesses locais ${ }^{18}$.

$\mathrm{O}$ entendimento das alteraçóes sobre a microbiota provocada pelo tratamento contra o câncer de cabeça e pescoço pode identificar aspectos de impacto na sobrevida do paciente, tornando sua compreensão fundamental para auxiliar no melhor planejamento e na reduçáo de reaçôes adversas ao paciente. Com base nos dados supracitados, a presente revisão sistemática concentrou-se em um aprofundamento no conteúdo acerca da mudança, colonização e prevalência de bactérias e fungos relacionados com a terapia antineoplásica em indivíduos acometidos por câncer de cabeça e pescoço, analisando produçôes científicas nacionais e internacionais.

\section{MÉTODO}

A prática baseada em evidências tem proporcionado um crescente aumento na produção das revisóes de literatura sistemática, que são consideradas estudos secundários, tendo pesquisas primárias como sua fonte de dados. Compreendem-se, por estudos primários, os artigos científicos que relatam os resultados de pesquisas observacionais ou experimentais ${ }^{19}$. Sendo assim, trata-se de uma revisão sistemática, realizada entre abril e novembro de 2020, conduzida conforme a metodologia Preferred Reporting Items for Sistematic Reviews and Meta-Analyses (PRISMA) ${ }^{20}$ e cadastrada no International Prospective Register of Systematic Reviews (PROSPERO) com número de registro CRD42021219974.

Durante esse período, foram avaliados diferentes tipos de estudos disponíveis nas bases de dados: Biblioteca Virtual em Saúde (BVS); Google Acadêmico; PubMed; e ScienceDirect, que contivessem os descritores indexados ao MeSH (Medical Subject Headings) ou os seus correspondentes no DeCS (Descritores em Ciências da Saúde): "head and neck neoplasms"," mouth neoplasms" e "microbiota" na língua inglesa e "neoplasias de cabeça e pescoço", "neoplasias bucais" e "microbiota" em português.

Por seguinte, a realização da estratégia de busca consistiu nas seguintes combinaçôes: "head and neck neoplasms" OR "mouth neoplasms" $A N D$ "microbiota", "neoplasias de cabeça e pescoço" $O R$ "neoplasias bucais" $A N D$ "microbiota". Como critérios de inclusão, foram selecionados artigos publicados entre abril de 2010 a abril de 2020 (disponíveis na íntegra em inglês ou português), que apresentassem pesquisas em seres humanos, avaliando a interação da microbiota oral e orofaríngea no tratamento oncológico.
Foram excluídos do estudo artigos de revisão, pesquisas que náo envolviam pacientes em uso de alguma terapia antineoplásica e artigos em outras línguas que não fossem o português e o inglês. Ainda neste estudo, foi utilizado o software Rayyan, desenvolvido pelo Qatar Computing Research Institute (QCRI), para o arquivamento, organização e seleção dos artigos de forma dinâmica e segura ${ }^{21}$.

Desse modo, após consulta às bases de dados e aplicação das estratégias de busca, ocorreu a exportação dos artigos para o Rayyan e foram identificados os que estavam em duplicidade nas bases. Os títulos e resumos dos artigos foram lidos para determinar a elegibilidade conforme os critérios de inclusão preestabelecidos, por meio de dois pesquisadores, e qualquer desacordo foi resolvido mediante discussão. Ainda, se a discordância persistisse, um terceiro pesquisador era consultado para obter consenso. Assim, objetivando a minimização de possíveis vieses de aferição dos estudos, como erros de interpretação e delineamento.

\section{RESULTADOS}

Ao realizar a busca nas bases de dados, foi encontrado um total de 670 artigos na soma dos artigos gerados das quatro bases de dados. Após a eliminação de 26 artigos duplicados, foram localizados 644 artigos. A base de dados ScienceDirect apresentou um maior número de trabalhos, totalizando 331 pesquisas. Desse total, 327 foram excluídos após a leitura dos resumos, por não se enquadrarem nos critérios de inclusão previamente estabelecidos. Na sequência, a base de dados Google Acadêmico localizou 218 artigos, sendo que 211 foram retirados após a leitura dos resumos. O PubMed exibiu 63 artigos; destes, após filtragem pela leitura dos títulos e dos resumos, foram excluídos 58 artigos. Já a BVS apresentou 32 publicaçôes; em seguida, com a leitura dos resumos, excluíram-se 28. Logo após a elegibilidade e a aplicação dos critérios de exclusão e inclusão, foram selecionados oito artigos. A Figura 1 apresenta a síntese do processo de seleção dos artigos.

A Tabela 1 mostra as características dos artigos incluídos quanto aos autores do respectivo estudo, ano de publicação, local, tipo de estudo, quantitativo de amostras, gênero, faixa etária e classificação do câncer.

As referências selecionadas nos resultados do presente trabalho foram publicadas no período de 2011 a 2019. Os artigos selecionados nesta revisão foram publicados nos seguintes periódicos científicos, Archives of Health Investigation, EBioMedicine, Journal of Oral Microbiology, Nutrición Hospitalaria, PloS One e Revista Brasileira de Cancerologia; ainda quanto ao tipo de estudo, foram 


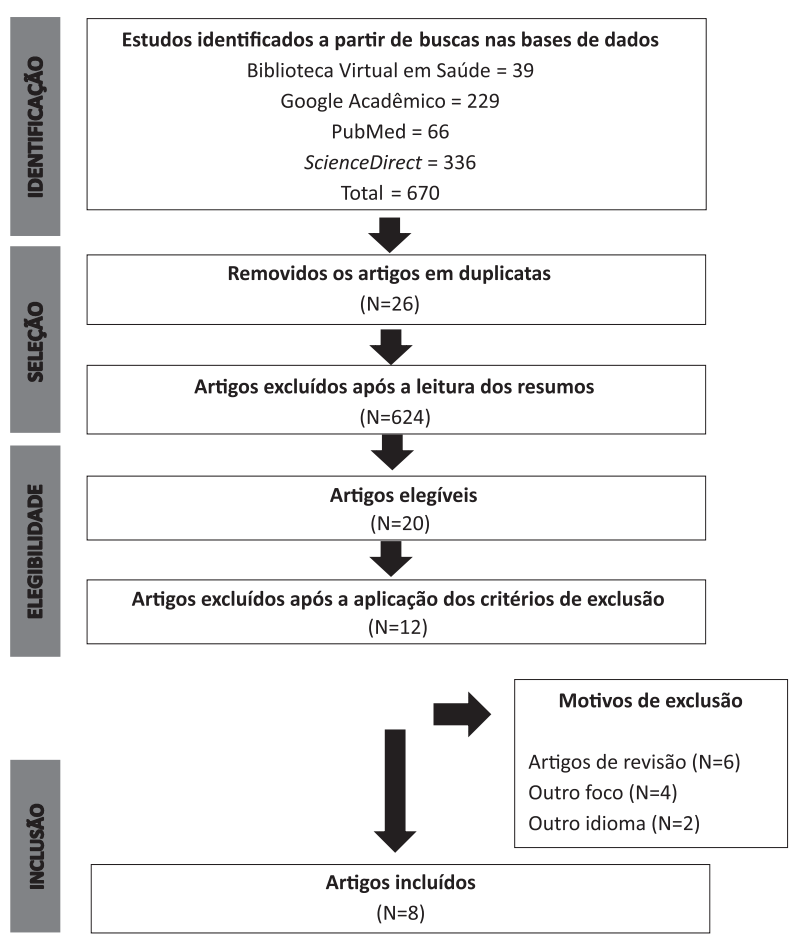

Figura 1. Fluxograma PRISMA para revisão sistemática, com descrição das fases de identificação dos estudos

obtidos estudo de coorte $(\mathrm{n}=7 ; 87,5 \%)$ e caso-controle coorte $(\mathrm{n}=1 ; 12,5 \%)$. A América do Sul e a Ásia foram os continentes de origem da maioria dos artigos incluídos na pesquisa, ambas apresentando $\mathrm{n}=3(37,5 \%)$ totalizando $\mathrm{n}=6(75 \%)$ com contribuiçóes oriundas do Brasil e China $(\mathrm{n}=3 ; 37,5 \% ; \mathrm{n}=3 ; 37,5 \%)$, seguidos da América do Norte $(\mathrm{n}=1 ; 12,5 \%)$ e Europa $(\mathrm{n}=1 ; 12,5 \%)$, cujas contribuiçóes foram respectivamente de Estados Unidos e Espanha. Não houve artigo selecionado de países da África e da Oceania.

Nos oito estudos incluídos, havia 257 participantes, sendo 153 (59,53\%) do gênero masculino, 54 (21,01\%) do gênero feminino e $50(19,45 \%)$ não foram identificados pelo autor da pesquisa. Dos 257 indivíduos totais, 12 eram pacientes do grupo controle que náo foram acometidos pelo câncer e 245 apresentavam algum câncer na região cabeça e pescoço, sendo a distribuição anatômica: nasofaringe $(n=50 ; 20,4 \%)$, laringe $(n=19 ; 7,75 \%)$, cavidade oral $(\mathrm{n}=9 ; 3,7 \%)$, língua $(\mathrm{n}=6 ; 2,44 \%)$, faringe $(\mathrm{n}=4 ; 1,63 \%)$ e $(\mathrm{n}=157 ; 64,08 \%)$ sem relato da região acometida pelo câncer.

O perfil histológico dos tumores relatados nas pesquisas foi de carcinoma ( $\mathrm{n}=196 ; 80 \%)$ e neoplasias malignas indiferenciadas ( $\mathrm{n}=6 ; 2,44 \%)$; em 43 indivíduos $(17,55 \%)$, não houve a classificação histológica. Ainda foi possível agrupar os tipos de carcinomas, sendo espinocelular ou de células escamosas ( $\mathrm{n}=137 ; 69,89 \%)$, basoescamoso $(n=4 ; 2,04 \%)$, células acinares $(n=4$;
$2,04 \%)$ e metastático do tipo linfoepitelial ( $\mathrm{n}=1 ; 0,51 \%)$. Em 25,51\% ( $n=50)$, houve apenas o relato de que se designava como carcinoma.

Em relação ao tipo de tratamento, todos os artigos $(\mathrm{n}=8 ; 100 \%)$ relataram a predominância da radioterapia para o tratamento do câncer de cabeça e pescoço com ou sem uso de outro meio terapêutico; por conseguinte, o tratamento com radioterapia concomitante com a quimioterapia ou com a quimioterapia de indução foi representado em cinco estudos (62,5\%). Em dois estudos (25\%), houve uso associado de radioterapia e cirurgia. Os achados acerca dos objetivos, tempo de coleta das amostras e conclusão dos estudos selecionados estão expostos na Tabela 2. Já as características das condiçōes odontológicas e os aspectos microbiológicos dos estudos que avaliaram a interação da microbiota frente ao tratamento antineoplásico de pacientes com câncer de cabeça e pescoço são demonstrados na Tabela 3 .

\section{DISCUSSÃO}

No presente estudo, observa-se que os pacientes do sexo masculino são mais acometidos pelo câncer de cabeça e pescoço, em concordância com as estatísticas mundiais $^{22}$. Entre os perfis histopatológicos, a maioria dos estudos apontou o carcinoma de células escamosas como o mais prevalente, dado em conformidade com a literatura científica ${ }^{23,24}$. A radioterapia foi a terapia mais utilizada para o tratamento de cânceres que atingem a região da cabeça e pescoço, esse dado corrobora a maioria dos protocolos mundiais de tratamento antineoplásico ${ }^{22}$.

Diante dos diversos estudos analisados, verificou-se que a microbiota da cavidade oral e da orofaringe sofre alteraçóes perante a terapia antineoplásica ${ }^{25-31}$. Sequelas advindas desses tratamentos como mucosite, xerostomia e depressão do sistema imune afetam diretamente na relação de homeostase entre os micro-organismos e a saúde do hospedeiro, tornando até mesmo micro-organismos já residentes em potenciais patógenos ${ }^{31-33}$.

Cinco dos estudos informaram os cuidados orais adotados para os pacientes: três deles realizaram um protocolo de adequaçáo do meio bucal com procedimentos periodontais, restauradores e cirúrgicos, além de instruçóes de higiene oral ${ }^{26,29,30}$ e dois deles realizaram apenas instruçôes de higiene oral25,27. Mesmo assim, em nenhum dos estudos selecionados, a instituição de cuidados orais consistiu em variável metodológica do estudo, visto que os cuidados foram instituídos para todos os pacientes. Os demais estudos não fizeram menção a qualquer tipo de intervenção odontológica ${ }^{28,31,33}$. Adicionalmente, um dos estudos que realizou adequação de meio bucal dos pacientes destacou que apenas 38\% dos pacientes 
Tabela 1. Características dos estudos que avaliaram a interação da microbiota frente ao tratamento antineoplásico de pacientes com câncer de cabeça e pescoço

\begin{tabular}{|c|c|c|c|c|c|c|}
\hline Autor/Ano & Local & $\begin{array}{l}\text { Tipo de } \\
\text { estudo }\end{array}$ & $\begin{array}{l}\text { Amostras } \\
\text { (N) }\end{array}$ & $\begin{array}{l}\text { Sexo dos } \\
\text { pacientes }\end{array}$ & $\begin{array}{l}\text { Faixa } \\
\text { etária }\end{array}$ & Classificação do câncer \\
\hline $\begin{array}{l}\text { Gaetti- } \\
\text { - Jardim } \\
\text { Jr et al., } \\
2011\end{array}$ & Brasil & $\begin{array}{l}\text { Estudo de } \\
\text { coorte }\end{array}$ & $\begin{array}{l}50 \\
\text { pacientes }\end{array}$ & $38 \mathrm{M}$ e $12 \mathrm{~F}$ & $\begin{array}{l}16 \text { a } 80 \\
\text { anos } \\
\text { (média } \\
59,5 \text { ) }\end{array}$ & $\begin{array}{l}44 \text { pacientes apresentaram } \\
\text { carcinoma espinocelular, } 4 \\
\text { carcinoma de células acinares, } 1 \\
\text { paciente apresentou carcinoma } \\
\text { espinocelular basaloide e outro } \\
\text { apresentou neoplasia maligna } \\
\text { indiferenciada }\end{array}$ \\
\hline $\begin{array}{l}\text { Simões et } \\
\text { al., } 2011\end{array}$ & Brasil & $\begin{array}{l}\text { Estudo de } \\
\text { coorte }\end{array}$ & $\begin{array}{l}21 \\
\text { pacientes }\end{array}$ & - & $\begin{array}{l}32 \text { a } 94 \\
\text { anos }\end{array}$ & $\begin{array}{l}\text { A mais acometida foi a base } \\
\text { da língua ( } 6 \text { casos) seguida } \\
\text { da laringe ( } 5 \text { casos). Em } 95 \% \\
\text { dos casos, o tipo histológico } \\
\text { encontrado foi o carcinoma } \\
\text { de células escamosas, sendo o } \\
\text { outro caso diagnosticado como } \\
\text { carcinoma metastático tipo } \\
\text { linfoepitelial }\end{array}$ \\
\hline $\begin{array}{l}\text { Hu et al., } \\
2013\end{array}$ & China & $\begin{array}{l}\text { Estudo de } \\
\text { coorte }\end{array}$ & 8 pacientes & - & $\begin{array}{l}26 \text { a } 70 \\
\text { anos }\end{array}$ & - \\
\hline $\begin{array}{l}\text { Souza et } \\
\text { al., } 2015\end{array}$ & Brasil & $\begin{array}{l}\text { Estudo de } \\
\text { coorte }\end{array}$ & $\begin{array}{l}50 \\
\text { pacientes }\end{array}$ & $36 \mathrm{Mel} 4 \mathrm{~F}$ & $\begin{array}{l}18 \text { a } 78 \\
\text { anos } \\
\text { (média } \\
51,3 \text { ) }\end{array}$ & $\begin{array}{l}42 \text { eram portadores de } \\
\text { carcinoma espinocelular, } 5 \\
\text { apresentavam neoplasias } \\
\text { malignas indiferenciadas, } \\
\text { além de } 3 \text { casos de carcinoma } \\
\text { basoescamoso }\end{array}$ \\
\hline $\begin{array}{l}\text { Vidal- } \\
\text {-Casariego } \\
\text { et al., } \\
2015\end{array}$ & Espanha & $\begin{array}{l}\text { Estudo de } \\
\text { coorte }\end{array}$ & $\begin{array}{l}35 \\
\text { pacientes }\end{array}$ & $26 \mathrm{M}$ e $9 \mathrm{~F}$ & $\begin{array}{l}\text { Média } \\
63,8\end{array}$ & $\begin{array}{l}14 \text { apresentaram câncer na } \\
\text { região da laringe, } 9 \text { na cavidade } \\
\text { oral, } 4 \text { na faringe e } 8 \text { em outras } \\
\text { regiões }\end{array}$ \\
\hline $\begin{array}{l}\text { Zhang et } \\
\text { al., } 2015\end{array}$ & China & $\begin{array}{l}\text { Caso- } \\
\text {-controle/ } \\
\text { coorte }\end{array}$ & $\begin{array}{l}21 \\
\text { pacientes } \\
\text { (12 grupo } \\
\text { controle; } 9 \\
\text { do grupo } \\
\text { caso) }\end{array}$ & - & - & $\begin{array}{l}\text { Carcinoma localizado na } \\
\text { nasofaringe }\end{array}$ \\
\hline $\begin{array}{l}\text { Zhu et al., } \\
2017\end{array}$ & China & $\begin{array}{l}\text { Estudo de } \\
\text { coorte }\end{array}$ & $\begin{array}{l}41 \\
\text { pacientes }\end{array}$ & $27 \mathrm{M} \mathrm{e} 14 \mathrm{~F}$ & $\begin{array}{l}22-75 \\
\text { anos } \\
\text { (média } \\
47,2 \text { ) }\end{array}$ & $\begin{array}{l}\text { Carcinoma localizado na } \\
\text { nasofaringe }\end{array}$ \\
\hline $\begin{array}{l}\text { Mougeot et } \\
\text { al; } 2019\end{array}$ & $\begin{array}{l}\text { Estados } \\
\text { Unidos }\end{array}$ & $\begin{array}{l}\text { Estudo de } \\
\text { coorte }\end{array}$ & $\begin{array}{l}31 \\
\text { pacientes }\end{array}$ & $26 \mathrm{Me} 5 \mathrm{~F}$ & $\begin{array}{l}24 \text { a } 84 \\
\text { anos } \\
\text { (média } \\
56,8 \text { ) }\end{array}$ & Carcinoma de células escamosas \\
\hline
\end{tabular}

Legendas: $\mathrm{M}=$ Masculino; $\mathrm{F}=$ Feminino.

procuraram tratamento odontológico ${ }^{30}$, enquanto outro estudo descreveu que apenas $36 \%$ dos pacientes seguiram a orientação dos centros de radioterapia e procuraram tratamento odontológico previamente à realização da radioterapia ${ }^{27}$.
O gênero Candida é o mais predominante entre os fungos residentes da cavidade oral ${ }^{32}$, contudo, as várias alteraçôes a que seu hospedeiro é submetido durante a terapia antineoplásica podem alterar sua posição harmônica no equilíbrio microbiano. Em seu estudo, 
Tabela 2. Características dos estudos que avaliaram a interação da microbiota frente ao tratamento antineoplásico de pacientes com câncer de cabeça e pescoço

\begin{tabular}{|c|c|c|c|c|}
\hline Autor/Ano & Objetivos & $\begin{array}{c}\text { Tempo de coleta das } \\
\text { amostras }\end{array}$ & Intervenções odontológicas & Conclusão \\
\hline $\begin{array}{l}\text { Gaetti-Jardim Jr } \\
\text { et al., } 2011\end{array}$ & $\begin{array}{l}\text { Avaliar a ocorrência de } \\
\text { leveduras, pseudomonas } \\
\text { e bactérias entéricas na } \\
\text { cavidade oral de pacientes } \\
\text { submetidos à RT para } \\
\text { tratamento de câncer de } \\
\text { cabeça e pescoço }\end{array}$ & $\begin{array}{l}\text { Antes do tratamento } \\
\text { odontológico e da } \\
\text { RT (estágio 1), } \\
\text { imediatamente após o } \\
\text { término da RT (estágio 2) } \\
\text { e } 30 \text { dias após o término } \\
\text { da RT (estágio 3) }\end{array}$ & $\begin{array}{l}\text { Apenas } 38 \% \text { dos pacientes procuraram } \\
\text { tratamento odontológico que consistiu em } \\
\text { extrações dentárias, tratamento periodontal } \\
\text { e procedimentos restauradores. Além disso, } \\
\text { todos os pacientes foram orientados a usar } 5 \\
\mathrm{ml} \text { de uma suspensão oral contendo } 100.000 \\
\mathrm{U} / \mathrm{ml} \text { de nistatina aquosa } 3 \text { vezes ao dia, } \\
\text { para prevenir a candidíase oral durante a RT }\end{array}$ & $\begin{array}{l}\text { Modificações no ambiente oral } \\
\text { por causa do tratamento com RT } \\
\text { parecem facilitar a colonização } \\
\text { da cavidade oral por membros } \\
\text { da família Enterobacteriaceae, } \\
\text { gêneros Enterococcus e Candida }\end{array}$ \\
\hline $\begin{array}{l}\text { Simões et al., } \\
2011\end{array}$ & $\begin{array}{l}\text { Identificar a presença de } \\
\text { espécies de Candida e } \\
\text { analisar a possibilidade } \\
\text { desse fungo atuar como } \\
\text { fator agravante da } \\
\text { mucosite em pacientes } \\
\text { portadores de câncer } \\
\text { de cabeça e pescoço, } \\
\text { que estejam sendo } \\
\text { submetidos ao tratamento } \\
\text { antineoplásico }\end{array}$ & $\begin{array}{l}\text { Período mínimo de } 2 \\
\text { semanas em tratamento } \\
\text { com RT apenas ou de RT } \\
\text { associada à QT }\end{array}$ & - & $\begin{array}{l}\text { Os pacientes estudados } \\
\text { apresentaram correlação positiva } \\
\text { entre lesões de mucosite oral e } \\
\text { colonização fúngica por Candida }\end{array}$ \\
\hline Hu et al., 2013 & $\begin{array}{l}\text { Explorar o microbioma } \\
\text { dinâmico central da } \\
\text { microbiota oral na placa } \\
\text { supragengival durante } 0 \\
\text { curso da RT de cabeça e } \\
\text { pescoço }\end{array}$ & $\begin{array}{l}\text { Todas as amostras foram } \\
\text { coletadas em } 7 \text { momentos } \\
\text { no prazo de } 7 \text { semanas. } \\
\text { As amostras coletadas } \\
\text { antes do tratamento, com } \\
\text { nenhuma dose recebida, } \\
\text { foram usadas como grupo } \\
\text { controle }\end{array}$ & $\begin{array}{l}\text { Avaliação da saúde bucal antes da } \\
\text { RT. Quando necessário, as lesões de } \\
\text { cárie eram restauradas, o tratamento } \\
\text { endodôntico realizado e os dentes duvidosos } \\
\text { extraídos. Os pacientes receberam instruções } \\
\text { de higiene oral, mas nenhuma terapêutica } \\
\text { especial com flúor foi adicionada }\end{array}$ & $\begin{array}{l}\text { Foram encontrados } 140 \text { gêneros } \\
\text { pertencentes a } 13 \text { filos. } 4 \text { filos } \\
\text { (Actinobacteria, Bacteroidetes, } \\
\text { Firmicutes e Proteobacteria) } \\
\text { e } 11 \text { gêneros (Streptococcus, } \\
\text { Actinomyces, Veillonella, } \\
\text { Capnocytophaga, Derxia, } \\
\text { Neisseria, Rothia, Prevotella, } \\
\text { Granulicatella, Luteococcus e } \\
\text { Gemella) foram encontrados em } \\
\text { todos os indivíduos, apoiando o } \\
\text { conceito de um microbioma central }\end{array}$ \\
\hline $\begin{array}{l}\text { Souza et al., } \\
2015\end{array}$ & $\begin{array}{l}\text { Avaliar a ocorrência } \\
\text { de micro-organismos } \\
\text { oportunistas da família } \\
\text { Enterobacteriaceae e dos } \\
\text { gêneros Enterococcus } \\
\text { e Staphylococcus na } \\
\text { microbiota bucal de } \\
\text { pacientes oncológicos } \\
\text { submetidos à RT de cabeça } \\
\text { e pescoço }\end{array}$ & $\begin{array}{l}\text { Antes do tratamento } \\
\text { radioterápico, } 15-22 \\
\text { dias após o início } \\
\text { do tratamento, } \\
\text { imediatamente após o } \\
\text { final da RT, } 30 \text { dias após } \\
\text { o tratamento, } 6 \text { e } 12 \\
\text { meses após a conclusão da } \\
\text { terapia }\end{array}$ & $\begin{array}{l}\text { Apenas } 36 \% \text { dos pacientes seguiram a } \\
\text { orientação dos centros de RT e procuraram } \\
\text { tratamento odontológico previamente à } \\
\text { realização da RT, de forma que apenas } 16 \% \\
\text { dos pacientes mostravam-se livres de cáries } \\
\text { no início do tratamento radioterápico. Ao } \\
\text { realizar as coletas das amostras, todos os } \\
\text { pacientes receberam orientaçoes sobre técnicas } \\
\text { de escovação, uso de fio dental e higiene de } \\
\text { dispositivos protéticos }\end{array}$ & $\begin{array}{l}\text { Os resultados sugeriram que a } \\
\text { colonização bucal por micro- } \\
\text {-organismos oportunistas foi } \\
\text { frequente e estável ao longo } \\
\text { do tempo, mas sem uma nítida } \\
\text { correlação com a saúde bucal } \\
\text { e a intensidade do tratamento } \\
\text { radioterápico }\end{array}$ \\
\hline $\begin{array}{l}\text { Vidal-Casariego } \\
\text { et al., } 2015\end{array}$ & $\begin{array}{l}\text { Demonstrar se a } \\
\text { modalidade de tratamento, } \\
\text { o estado nutricional e a flora } \\
\text { orofaríngea contribuem } \\
\text { para o desenvolvimento } \\
\text { de mucosite no câncer de } \\
\text { cabeça e pescoço tratado } \\
\text { com RT }\end{array}$ & $\begin{array}{l}\text { Antes da RT } \\
\text { (recrutamento), no meio } \\
\text { do período de RT e após o } \\
\text { término da RT }\end{array}$ & - & $\begin{array}{l}0 \text { isolamento orofaríngeo de } \\
\text { patógenos bacterianos pode } \\
\text { favorecer o desenvolvimento e } 0 \\
\text { agravamento da mucosite oral }\end{array}$ \\
\hline
\end{tabular}


Tabela 2. continuação

\begin{tabular}{|c|c|c|c|c|}
\hline Autor/Ano & Objetivos & $\begin{array}{c}\text { Tempo de coleta das } \\
\text { amostras }\end{array}$ & Intervenções odontológicas & Conclusão \\
\hline $\begin{array}{l}\text { Zhang et al., } \\
2015\end{array}$ & $\begin{array}{l}\text { Investigar a relação entre } \\
\text { função salivar, microbiota } \\
\text { oral e ausência de cárie por } \\
\text { radiação }\end{array}$ & 12 a 36 meses após a RT & - & $\begin{array}{l}\text { Não foi encontrada correlaçãa } \\
\text { clara entre as características da } \\
\text { microbiota salivar do paciente e } \\
\text { a cárie por radiação } 1 \text { ano após } \\
\text { a RT. Esses resultados sugerem } \\
\text { que a função salivar em pacientes } \\
\text { irradiados não se recupera } \\
\text { completamente após } 12 \text { a } 36 \\
\text { meses, mas o valor do pH e a } \\
\text { capacidade de tamponamento da } \\
\text { saliva retornam ao normal após } 1 \\
\text { ano ou mais após a RT }\end{array}$ \\
\hline $\begin{array}{l}\text { Zhu et al., } \\
2017\end{array}$ & $\begin{array}{l}\text { Investigar alterações } \\
\text { dinâmicas no perfil } \\
\text { bacteriano oral e } \\
\text { correlações entre a } \\
\text { gravidade da mucosite e } \\
\text { as alterações bacterianas } \\
\text { durante a RT }\end{array}$ & $\begin{array}{l}\text { Antes da irradiação, após } \\
a 5^{a}, 10^{a}, 15^{a}, 20^{a}, 25^{a} \text {, } \\
30^{a} \text { e } 35^{a} \text { irradiação }\end{array}$ & $\begin{array}{l}\text { Antes do início do tratamento com radiação, } \\
\text { todos os pacientes receberam } 1 \text { exame } \\
\text { clínico completo e instruções de higiene } \\
\text { oral. Os procedimentos cirúrgicos foram } \\
\text { realizados em pacientes com cárie, doenças } \\
\text { pulpares e gengivite, incluindo limpeza } \\
\text { dentária profissional, obturação, tratamento } \\
\text { endodôntico e exodontia de dentes não } \\
\text { restauráveis }\end{array}$ & $\begin{array}{l}\text { As alterações da microbiota oral } \\
\text { estão correlacionadas com a } \\
\text { progressão e com o agravamento } \\
\text { da mucosite induzida por RT } \\
\text { em pacientes com carcinoma } \\
\text { nasofaríngeo }\end{array}$ \\
\hline $\begin{array}{l}\text { Mougeot et al., } \\
2019\end{array}$ & $\begin{array}{l}\text { Caracterizar o microbioma } \\
\text { oral de pacientes com CCP } \\
\text { submetidos à RT na linha } \\
\text { de base (TO) e } 6 \text { (T6) e } \\
18 \text { (T18) meses após a } \\
\text { RT, e determinar se havia } \\
\text { relação com aumento de } \\
\text { cárie }\end{array}$ & $\begin{array}{l}\text { Em } 3 \text { momentos } \\
\text { denominados antes } \\
\text { da RT, } 6 \text { meses após o } \\
\text { tratamento com RT e } 18 \\
\text { meses após a RT }\end{array}$ & $\begin{array}{l}\text { As recomendações de higiene oral incluíam } \\
\text { a escovação de pelo menos } 2 \text { vezes ao dia, } 0 \\
\text { uso do fio dental diariamente e a aplicação } \\
\text { diária de creme dental com flúor }\end{array}$ & $\begin{array}{l}\text { Esses dados sugerem que a } \\
\text { diferença de base no microbioma } \\
\text { é um fator importante que pode } \\
\text { explicar o resultado da cárie } \\
\text { dentária em pacientes com câncer } \\
\text { de cabeça e pescoço tratados com } \\
\text { radiação. Tais dados sugerem } \\
\text { um papel cariogênico de } P \text {. } \\
\text { melaninogenica e um potencial } \\
\text { papel protetor de certas espécies } \\
\text { bacterianas como A. defectiva, } \\
\text { porém estudos mais detalhados } \\
\text { são necessários para confirmação }\end{array}$ \\
\hline
\end{tabular}

Legendas: $\mathrm{RT}$ = Radioterapia; $\mathrm{QT}$ = Quimioterapia; $\mathrm{CCP}=$ Câncer de cabeça e pescoço.

Vidal-Casariego et al..$^{28}$ cultivaram leveduras em 35,3\% dos pacientes totais com câncer em tratamento, tendo $11(97,7 \%)$ amostras que corresponderam à espécie Candida albicans e uma $(8,3 \%)$ amostra à Candida tropicalis $^{28}$, com número inferior ao da variedade de espécies isoladas no estudo de Gaetti-Jardim Jr et al. ${ }^{30}$, que identificaram, em $84 \%$ dos pacientes após 30 dias da sessão radioterápica, as seguintes espécies de fungos: Candida albicans, C. tropicalis, C. krusei, C. glabrata e C. parapsilosis. Mesmo com as orientaçóes repassadas do uso de suspensão de nistatina durante a radioterapia, ocorreu a proliferação de fungos Candida spp., sendo esse fator ligado principalmente à baixa adesão do paciente, sendo importante o acompanhamento odontológico na aderência de uma terapêutica eficiente ${ }^{30}$.

Além disso, o estudo de Gaetti-Jardim Jr et al. ${ }^{30}$ ainda permitiu identificar um aumento de $78 \%$ dos fungos Candida spp. imediatamente após o término do tratamento radioterápico e de $84 \% 30$ dias após a última sessão de radioterapia, estando ainda associados à manifestação da mucosite de graus III e IV ${ }^{30}$. Esse dado é compatível com o estudo de Simóes et al. ${ }^{31}$, que mostraram um desenvolvimento de candidíase em associação com mucosite oral graus III e IV, comprovando a correlação positiva entre as lesôes e a colonização fúngica por Candida ${ }^{31}$. 
Tabela 3. Características das condições odontológicas e aspectos microbiológicos dos estudos que avaliaram a interação da microbiota frente ao tratamento antineoplásico de pacientes com câncer de cabeça e pescoço

\begin{tabular}{|c|c|c|c|}
\hline Autor/Ano & Condições odontológicas & Alterações bacteriológicas da microbiota & Alterações micológicas da microbioła \\
\hline $\begin{array}{l}\text { Gaetti-Jardim Jr } \\
\text { et al., } 2011\end{array}$ & $\begin{array}{l}\text { A presença de próteses totais ou } \\
\text { condições dentárias (ou seja, presença } \\
\text { ou ausência de cárie cavitada) não } \\
\text { influenciou a ocorrência de mucosite } \\
\text { (teste do qui-quadrado, } \mathrm{p}=0,139 \text { ). } \\
0 \text { estado periodontal não influenciou } \\
\text { a ocorrência de mucosite (teste qui- } \\
\text {-quadrado, } \mathrm{p}=0,779 \text { ). A ocorrência } \\
\text { de mucosite foi associada ao } \\
\text { desenvolvimento de xerostomia (teste } \\
\text { qui-quadrado, } \mathrm{p}=0,021 \text { ) }\end{array}$ & $\begin{array}{l}\text { Inicialmente, antes da RT, micro-organismos } \\
\text { entéricos foram cultivados de amostras de } \\
\text { mucosa oral, sendo identificados como E. faecalis } \\
\text { e Citrobacter freundii. Além disso, } 30 \text { dias após } \\
\text { a RT, bactérias entéricas e pseudomonas foram } \\
\text { cultivadas em } 77,8 \% \text { dos pacientes edêntulos e em } \\
46,9 \% \text { dos pacientes dentados. Ademais, pacientes } \\
\text { desdentados apresentaram maior frequência } \\
\text { de colonização oral por micro- -organismos } \\
\text { entéricos ( } p=0,038 \text { ) e a RT foi associada a um } \\
\text { aumento significativo na ocorrência desses micro- } \\
\text {-organismos ( }<<0,001 \text { ) }\end{array}$ & $\begin{array}{l}15 \text { pacientes (30\%) foram inicialmente } \\
\text { colonizados por Candida spp. Aumentando } \\
\text { para } 78 \% \text { logo após a RT e } 84 \% 30 \text { dias após } \\
\text { a RT; esse aumento não estava diretamente } \\
\text { relacionado ao estado dentário ou periodontal. } \\
30 \text { dias após a RT, as leveduras foram } \\
\text { recuperadas de todos os indivíduos edêntulos } \\
\text { e de } 75 \% \text { dos pacientes dentados. Os isolados } \\
\text { de fungos foram identificados como Candida } \\
\text { albicans, C. tropicalis, C. krusei, C. glabrata } \\
\text { ou C. parapsilosis. A presença de C. albicans } \\
\text { concomitantemente com espécies não albicans de } \\
\text { Candida foi particularmente comum após RT }\end{array}$ \\
\hline $\begin{array}{l}\text { Simões et al., } \\
2011\end{array}$ & - & - & $\begin{array}{l}\text { A maioria dos pacientes estudados recebeu } \\
\text { irradiação entre } 2.880 c G y \text { e } 6.160 c G y \text { e, em } \\
\text { apenas } 3 \text { pacientes, não foi detectada proliferação } \\
\text { de fungos do gênero Candida. A colonização } \\
\text { fúngica foi observada em } 19 \text { casos. Os pacientes } \\
\text { estudados apresentaram correlação positiva entre } \\
\text { lesões de mucosite oral e colonização fúngica }\end{array}$ \\
\hline Hu et al., 2013 & $\begin{array}{l}\text { Foram excluídos do estudo pacientes } \\
\text { que apresentassem lesões de cárie } \\
\text { cavitadas não tratadas ou abscessos } \\
\text { orais e aqueles incapazes de manter a } \\
\text { higiene oral durante o estudo }\end{array}$ & $\begin{array}{l}\text { Apenas } 2 \text { gêneros (Streptococcus e Actinomyces) } \\
\text { estiveram presentes em todos os pontos durante } \\
\text { a RT no tempo de } 10 \text { Gy a } 60 \text { Gy. A abundância } \\
\text { relativa de Streptococcus oscilou entre 21,33\% } \\
\text { (20 Gy) e 3,2\% ( } 50 \text { Gy), e a de Actinomyces } \\
\text { permaneceu estável (cerca de 4,48\% a 4,85\%) } \\
\text { no estágio inicial dos pontos de tempo ( } 10 \text { Gy, } 20 \\
\text { Gy, } 30 \text { Gy), mas subiu para } 23,32 \% \text { no ponto de } \\
\text { tempo de } 50 \text { Gy. Vários outros gêneros, incluindo } \\
\text { Veillonella, Capnocytophaga, Derxia, Neisseria, } \\
\text { Rothia, Prevotella, Granulicatella, Luteococcus e } \\
\text { Gemella foram identificados em algum momento } \\
\text { nos sujeitos durante a RT ( } 10 \text { Gy-60 Gy) }\end{array}$ & \\
\hline $\begin{array}{l}\text { Souza et al., } \\
2015\end{array}$ & $\begin{array}{l}\text { Os pacientes apresentavam condições } \\
\text { bastante variáveis de higiene bucal, } \\
\text { sendo que } 18 \% \text { apresentaram uma } \\
\text { higiene satisfatória, enquanto } 36 \% \text {, } \\
\text { higiene regular, } 46 \% \text { condições } \\
\text { precárias de higiene. As condições } \\
\text { de higiene bucal mostraram uma } \\
\text { significativa deterioração durante } \\
\text { e imediatamente após a RT, } \\
\text { evidenciada pelo maior acúmulo } \\
\text { de biofilme visível (teste de qui- } \\
\text {-quadrado, } p=0,042 \text { ). Observou- } \\
\text {-se que todos os pacientes que } \\
\text { desenvolveram mucosite graus III e } \\
\text { IV apresentavam condições precárias } \\
\text { de higiene dental (teste de qui- } \\
\text {-quadrado, } p<0,001 \text { ) }\end{array}$ & $\begin{array}{l}\text { Identificou-se a presença de espécies da família } \\
\text { Enterobacteriaceae, Enterococos e Estafilococos. } \\
\text { Inicialmente, acreditou-se na hipótese de que } \\
\text { as condições precárias de higiene bucal, comuns } \\
\text { nos pacientes estudados, pudessem constituir o } \\
\text { principal elemento que condicionava a transmissão } \\
\text { dos micro-organismos encontrados, o que poderia } \\
\text { ser potencializado pelo uso de próteses, além } \\
\text { da ocorrência de mucosite e xerostomia, que } \\
\text { deteriorariam as já precárias condições bucais. } 0 \\
\text { papel desses fatores isoladamente sugeria que a } \\
\text { presença dos micro-organismos nos pacientes seria } \\
\text { transitória. Entretanto, os micro-organismos-alvo } \\
\text { estiveram presentes, em parcela significativa dos } \\
\text { pacientes, ao longo do tempo de avaliação, tendo } \\
\text { aumentado com a RT e se mantido em patamares } \\
\text { elevados mesmo } 12 \text { meses após a conclusão }\end{array}$ & \\
\hline
\end{tabular}


Tabela 3. continuação

\begin{tabular}{|c|c|c|c|}
\hline Autor/Ano & Condições odontológicas & Alterações bacteriológicas da microbiota & Alterações micológicas da microbiota \\
\hline $\begin{array}{l}\text { Vidal-Casariego } \\
\text { et al., } 2015\end{array}$ & - & $\begin{array}{l}\text { Colonização bacteriana foi encontrada em } \\
28,6 \% \text { (10/27) de pacientes, e as espécies } \\
\text { isoladas incluíram Staphylococcus aureus (3/10), } \\
\text { Escherichia coli (3/10), Pseudomonas aeruginosa } \\
(2 / 10) \text {, Serratia spp. }(2 / 10) \text {, Enterobacter cloacae } \\
(2 / 10) \text {, Citrobacter freundii (2/10), Klebsiella } \\
\text { oxytoca (1/10) e Agrobacterium radiobacter } \\
\text { (1/10). Em } 4 \text { casos, mais de } 1 \text { espécie bacteriana } \\
\text { foi isolada }\end{array}$ & $\begin{array}{l}\text { Os fungos foram cultivados em } 35,3 \% \text { (12/35) de } \\
\text { pacientes: } 11 \text { amostras corresponderam à Candida } \\
\text { albicans e } 1 \text { amostra à Candida tropicalis }\end{array}$ \\
\hline $\begin{array}{l}\text { Zhang et al., } \\
2015\end{array}$ & $\begin{array}{l}\text { Foram incluídos no estudo indivíduos } \\
\text { que apresentassem cárie dentária } \\
\text { recente após RT, e excluídos aqueles } \\
\text { que demonstrassem periodontite }\end{array}$ & $\begin{array}{l}\text { Foram observados } 11 \text { gêneros de (Streptococcus, } \\
\text { Neisseria, Scardovia, Porphyromonas, } \\
\text { Fusobacteria, Lautropia, Veillonella, } \\
\text { Capnocytophaga, Rithia, Leptotrichia e Prevotella). } \\
\text { Sendo Streptococcus spp. e Neisseria spp. presentes } \\
\text { em mais de } 80 \% \text { das amostras }\end{array}$ & - \\
\hline Zhu et al., 2017 & $\begin{array}{l}\text { Foram excluídos do estudo os } \\
\text { pacientes, assim que apresentavam } \\
\text { má higiene bucal e/ou desenvolveram } \\
\text { formas graves de doenças } \\
\text { periodontais }\end{array}$ & $\begin{array}{l}\text { Houve abundância relativa significativamente } \\
\text { maior de Streptococcus nos casos de mucosite de } \\
\text { graus III e IV. Além disso, em comparação com } \\
\text { indivíduos saudáveis, os pacientes oncológicos } \\
\text { incluídos neste estudo abrigavam abundâncias } \\
\text { significativamente maiores de Pseudomonas, } \\
\text { Pediococcus e Oscillibacter na orofaringe, todos os } \\
\text { quais foram mostrados por estarem associados a } \\
\text { infecções humanas }\end{array}$ & - \\
\hline $\begin{array}{l}\text { Mougeot et al., } \\
2019\end{array}$ & $\begin{array}{l}\text { Foram estudados } 2 \text { grupos, } 1 \text { de } \\
\text { pacientes com aumento da cárie } \\
\text { dentária e outro de pacientes sem } \\
\text { aumento da cárie dentária }\end{array}$ & $\begin{array}{l}\text { A espécie Streptococcus mutans aumentou no } \\
\text { período de } 6 \text { meses após o tratamento, nos } \\
\text { pacientes com e sem aumento da cárie dentária. Já } \\
\text { a espécie Prevotella melaninogenica diminuiu no } \\
\text { período de } 6 \text { meses após a terapia antineoplásica } \\
\text { nos pacientes sem aumento da cárie dentária. } \\
\text { Ainda, a da espécie associada à saúde, Abiotrophia } \\
\text { defeituosa, diminuiu no grupo de pacientes com } \\
\text { aumento da cárie dentária }\end{array}$ & - \\
\hline
\end{tabular}

Legenda: $\mathrm{RT}=$ Radioterapia .

Ainda nos isolados de Gaetti-Jardim Jr et al. ${ }^{30}$, antes da radioterapia, os micro-organismos entéricos foram cultivados a partir de amostras de mucosa oral de quatro pacientes desdentados $(22,5 \%)$ e de biofilmes subgengivais de três pacientes dentados $(9,4 \%)$, sendo identificadas bactérias exógenas com potencial patogênico como $E$. faecalis em seis amostras de pacientes desdentados ou dentados e Citrobacter freundii em uma amostra de um paciente desdentado. Além disso, 30 dias após o término do tratamento radioterápico, bactérias entéricas e pseudomonas foram cultivadas em $77,8 \%$ dos pacientes desdentados e em $46,9 \%$ dos pacientes dentados. Estabelecendo como os gêneros mais frequentemente detectados Citrobacter, Enterobacter, Enterococcus, Klebsiella, Morganella, Proteus e Pseudomonas. Nesse sentido, pacientes desdentados apresentaram maior frequência de colonização oral por micro-organismos entéricos, e a radioterapia foi associada a um aumento significativo na ocorrência desses micro-organismos. A ocorrência de micro-organismos entéricos não foi associada à gengivite ou à periodontite, mas foram observadas com maior frequência entre os consumidores de tabaco e os pacientes com mucosite nível III ou IV ${ }^{30}$.

Na pesquisa de Souza et al. ${ }^{27}$, foi possível encontrar, após o início da radioterapia, que o primeiro grupo microbiano, cuja prevalência se elevou, foi o dos membros da família Enterobacteriaceae, nas primeiras duas a três semanas de tratamento e na conclusáo da radioterapia, mantendo-se frequentes no biofilme sub e supragengival, saliva e mucosa dos irradiados nos 12 meses após a radioterapia. A ocorrência dos cocos Gram-positivos não se elevou no 
início da radioterapia, mas $E$. faecalis se mostrou mais prevalente ao final, mantendo-se em patamares elevados de ocorrência um ano após a conclusão do tratamento radioterápico. Resultados semelhantes foram obtidos para os gêneros Enterococcus e Staphylococcus, enquanto E. faecium não teve sua ocorrência significativamente modificada pela radioterapia. A presença de membros da família Enterobacteriaceae e E. faecalis mostrou-se relacionada com as condiçóes de higiene bucal, predominando entre os pacientes com higiene precária. Após 12 meses de avaliação, observou-se que, apenas nos pacientes que desenvolveram mucosite oral graus II e III, houve colonização por Enterococcus spp. e/ou bastonetes Gram-negativos da família Enterobacteriaceae ${ }^{27}$.

Nos resultados de Vidal-Casariego et al. ${ }^{28}$, verificou-se o isolamento na orofaringe de patógenos em 28,6\% dos pacientes que desenvolveram mucosite oral; as cepas isoladas incluíram Staphylococcus aureus, Escherichia coli, Pseudomonas aeruginosa, Serratia spp, Enterobacter cloacae, Citrobacter freundii, Klebsiella oxytoca, e Agrobacterium radiobacter. Não houve diferença significativa na colonização microbiana quanto ao sexo do paciente, local e estágio do câncer $^{28}$.

No estudo de Hu et al. ${ }^{29}$, amostras da placa supragengival reunida das superfícies bucogengivais do primeiro molar superior em pacientes em radioterapia durante seis semanas de tratamento identificou 11 gêneros microbianos (Streptococcus, Actinomyces, Veillonella, Capnocytophaga, Derxia, Neisseria, Rothia, Prevotella, Granulicatella, Luteococcus e Gemella), que foram designados como um microbioma nuclear neste estudo, variando sua abundância relativa durante o curso da radioterapia. $\mathrm{O}$ gênero Streptococcus se apresentou com maior prevalência em todos os sujeitos durante as seis sessóes e consistiu em grande número de espécies cariogênicas e não cariogênicas, incluindo S. sobrinus, S. mutans, S. oralis, $S$. mitis e $S$. pneumonia. O gênero Actinomyce obteve segunda maior prevalência ${ }^{29}$. Em concordância, as pesquisas de Zhu et al. ${ }^{26}$ também identificaram abundância relativa significativamente maior de Streptococcus em pacientes que apresentaram mucosite de graus III e IV, relacionada também com a progressão e o agravamento da mucosite induzida por radioterapia em pacientes com carcinoma nasofaríngeo. No mesmo estudo, em alguns pacientes, foram detectadas abundâncias significativamente de Pseudomonas, Pediococcus e Oscillibacter em orofaringe, todas as quais demonstraram estar associadas a infecçōes humanas. Esses resultados mostraram que as mudanças na comunidade microbiana oral correlacionadas com a progressão e agravamento da mucosite induzida por radioterapia em pacientes oncológicos e a busca de estratégias odontológicas para o tratamento precoce e prevenção da incidência de mucosite grave durante a radioterapia são essenciais ${ }^{26}$.

Pacientes submetidos à radioterapia apresentam risco elevado de cárie de radiação, sendo uma das complicaçóes tardias do tratamento. Mougeot et al. ${ }^{25}$ realizaram um estudo com dois grupos de pacientes, um com aumento da cárie dentária e outro sem aumento. Foi observada diminuição da espécie Prevotella melaninogenica, frequentemente associada à cárie em crianças pequenas, em seis meses após a radioterapia no grupo de indivíduos sem aumento da cárie. Enquanto as espécies associadas à saúde do hospedeiro, Abiotrophia defectiva, diminuíram no grupo de pacientes com aumento da cárie dentária. Ainda, foi observado que a predominância da espécie Streptococcus mutans aumentou em seis meses após a radioterapia nos pacientes dos dois grupos, micro-organismo intimamente associado à cárie. Consequentemente, se torna fundamental observar como a radioterapia pode provocar alteraçóes nos perfis da microbiota nos pacientes oncológicos, e assim resultar em fraquezas de defesa do hospedeiro que podem ser aumentadas pela não conformidade com as boas práticas de higiene oral ${ }^{25}$.

Contudo, Zhang et al. ${ }^{33}$ realizaram um estudo do tipo coorte-controle no qual analisaram a saliva de pacientes após 12 a 36 meses do fim do tratamento radioterápico, encontrando $80 \%$ do total das bactérias pertencentes às espécies Streptococcus spp. e Neisseria spp., sendo que distribuiçôes semelhantes foram detectadas no grupo controle. Dessa forma, não ocorreu correlaçáo clara entre as características da microbiota salivar do paciente e a cárie por radiaçáo um ano após o tratamento. Ainda sugeriram que a função salivar em pacientes irradiados não se recupera completamente após 12 a 36 meses, mas o valor do $\mathrm{pH}$ e a capacidade de tamponamento da saliva retornam às condiçốes normais, após um ano, o que permite melhor controle na homeostase da microbiota ${ }^{33}$.

Fundamentalmente, Zhang et al..$^{33}$ encontraram níveis mais baixos de índice de placa nos participantes do grupo pacientes sem cárie de radiação do que nos participantes do grupo pacientes exibindo cárie de radiação $(\mathrm{p}=0,038)$. Visto que o índice de placa é uma avaliação direta do nível de higiene oral, uma diferença significativa no índice de placa indica que o grupo pacientes sem cárie de radiação tem melhor higiene oral do que o outro grupo. No entanto, mais estudos de caráter longitudinais e com maior população amostral devem ser realizados para relacionar a má higiene oral como um fator causal no desenvolvimento de cárie por radiação ${ }^{33}$.

Esta revisão buscou mostrar um panorama presente na literatura dos últimos dez anos, acerca da temática do impacto do tratamento antineoplásico sobre a microbiota da cavidade oral e orofaríngea em pacientes acometidos 
pelo câncer na regiáo cabeça e pescoço, seguindo a metodologia PRISMA, no entanto, pela qualidade heterogênea dos estudos selecionados neste artigo, é inviável a realização de uma metanálise.

\section{CONCLUSÃO}

Após análise dos artigos selecionados, os autores relataram presença de processos patológicos, como mucosites e cáries dentárias, em grande parte dos pacientes envolvidos em suas pesquisas, sendo estas causadas por micro-organismos presentes na microbiota oral e orofaríngea, sendo os mais frequentemente relatados: bactérias da espécie Streptococcus spp. e fungos da espécie Candida spp. Além disso, o tratamento com radiação influencia no comportamento desse microbioma por meio do comprometimento funcional do organismo, alterando seu sistema imunológico, função salivar, entre outros. Esses fatores contribuem para o aumento da proliferação microbiológica, elevando as chances de os pacientes em tratamento ou pós-tratamento desenvolverem processos patológicos na cavidade oral e orofaríngea pelos micro-organismos. Tendo em vista essa condição, o entendimento das alteraçóes do microbioma oral provocadas pelo tratamento contra o câncer de cabeça e pescoço e uma participação ativa da equipe de odontologia hospitalar permitem um melhor planejamento para atender às necessidades dos pacientes, proporcionando uma melhor saúde bucal e reduzindo o impacto provocado pelo tratamento antineoplásico.

\section{CONTRIBUIÇÕES}

Todos os autores contribuíram substancialmente na concepção e/ou no planejamento do estudo; na obtençáo, análise e/ou interpretaçáo dos dados; na redação e/ou revisão crítica; e aprovaram a versão final a ser publicada.

\section{DECLARAÇÃO DE CONFLITO DE INTERESSES}

Nada a declarar.

\section{FONTES DE FINANCIAMENTO}

Não há.

\section{REFERÊNCIAS}

1. Colombo J, Rahal P. Alteraçôes genéticas em câncer de cabeça e pescoço. Rev Bras Cancerol. 2009;55(2):16574. doi: https://doi.org/10.32635/2176-9745. RBC.2009v55n2.1648
2. Instituto Nacional de Câncer José Alencar Gomes da Silva. Estimativa 2020: incidência de câncer no Brasil [Internet]. Rio de Janeiro: INCA; 2019 [acesso 2020 maio 25]. Disponível em: https://www.inca.gov.br/sites/ ufu.sti.inca.local/files/media/document/estimativa-2020incidencia-de-cancer-no-brasil.pdf

3. Instituto Nacional de Câncer José Alencar Gomes da Silva. Dia Nacional de Combate ao Câncer: estimativa 2016: incidência de câncer no Brasil [Internet]. Rio de Janeiro: INCA; 2015 [acesso 2020 maio 25]. Disponível em: http://www.oncoguia.org.br/pub//10_advocacy/ Estimativas_INCA.pdf [Apresentação em Powerpoint].

4. Lee SC, Tang IP, Avatar SP, et al. Head and neck cancer: possible causes for delay in diagnosis and treatment. Med J Malaysia. 2011;66(2):101-4.

5. Lambert R, Sauvaget C, Camargo Cencela M, et al. Epidemiology of cancer from the oral cavity and oropharynx. Eur J Gastroenterol Hepatol. 2011;23(8):633-41. doi: https://doi.org/10.1097/ MEG.0b013e3283484795

6. Chen T, Yu WH, Izard J. et al. The human oral microbiome database: a web accessible resource for investigating oral microbe taxonomic and genomic information. Database (Oxford). 2010;2010:baq013. doi: https://doi.org/10.1093/database/baq013

7. Sampaio-Maia B, Caldas IM, Pereira ML, et al. The oral microbiome in health and its implication in oral and systemic diseases. Adv Appl Microbiol. 2016;97:171-210. doi: https://doi.org/10.1016/bs.aambs.2016.08.002

8. Jenkinson HF, Lamont RJ. Oral microbial communities in sickness and in health. Trends Microbiol. 2005;13(12):589-95. doi: https://doi.org/10.1016/j. tim.2005.09.006

9. Lemos JA, Palmer SR, Zeng L, et al. The Biology of Streptococcus mutans. Microbiol Spectr. 2019;7(1):GPP30051-2018. doi: https://doi.org/10.1128/microbiolspec. GPP3-0051-2018

10. Komiyama EY, Lepesqueur LSS, Yassuda CG, et al. Enterococcus species in the oral cavity: prevalence, virulence factors and antimicrobial susceptibility. PloS One. 2016;11(9):e0163001. doi: https://doi. org/10.1371/journal.pone.0163001

11. Leão-Vasconcelos LSNO, Lima ABM, Costa DM, et al. Enterobacteriaceae isolates from the oral cavity of workers in a Brazilian oncology hospital. Rev Inst Med Trop São Paulo. 2015;57(2):121-7. doi: https://doi.org/10.1590/ S0036-46652015000200004

12. Ghannoum MA, Jurevic RJ, Mukherjee PK, et al. Characterization of the oral fungal microbiome (Mycobiome) in healthy individuals. PLoS Pathog. 2010;6(1):e1000713. doi: https://doi.org/10.1371/ journal.ppat. 1000713

13. Moon JH, Lee J. Probing the diversity of healthy oral microbiome with bioinformatics approaches. BMB Rep. 
2016;49(12):662-570. doi: https://doi.org/10.5483/ bmbrep.2016.49.12.164

14. Costalonga M, Herzberg MC. The oral microbiome and the immunobiology of periodontal disease and caries. Immunol Lett. 2014;162(2 Pt A):22-38. doi: https:// doi.org/10.1016/j.imlet.2014.08.017

15. Nasry B, Choong C, Flamiatos E, et al. Diversity of the oral microbiome and dental health and disease. Int J Clin Med Microbiol. 2016;1(1):1-8. doi: https://doi. org/10.15344/2456-4028/2016/108

16. Terai T, Okumura T, Imai $S$, et al. Screening of probiotic candidates in human oral bacteria for the prevention of dental disease. PLoS One. 2015;10(6):e0128657. doi: https://doi.org/10.1371/journal.pone.0128657

17. Kim BS, Han DH, Lee H, et al. Association of salivary microbiota with dental caries incidence with dentine involvement after 4 years. J Microbiol Biotechnol. 2018;28(3):454-64. doi: https://doi.org/10.4014/ jmb. 1710.10028

18. Instituto Latino-Americano de Sepse [Internet]. Sáo Paulo: Sepse; c2016. Santa Casa faz alerta à sociedade no Dia Mundial de Combate à Sepse; 2016 dez 6 [acesso 2020 jun 3]. Disponível em: https://ilas.org.br/ interacao/? $\mathrm{p}=230$

19. Galvão TF, Pereira MG. Revisões sistemáticas da literatura: passos para sua elaboração. Epidemiol Serv Saúde. 2014.;23(1):183-4. doi: http://doi.org/10.5123/ S1679-49742014000100018

20. Moher D, Liberati A, Tetzlaff J, et al. Preferred reporting items for systematic reviews and meta-analyses: the PRISMA statement. PLoS Med. 2009;6(7):e1000097. doi: http://doi.org/10.1371/journal.pmed.1000097

21. Ouzzani M, Hammady H, Fedorowicz Z, et al. Rayyan-a web and mobile app for systematic reviews. Syst Rev. 2016;5:210. doi: https://doi.org/10.1186/s13643-0160384-4

22. Sung H, Ferlay J, Siegel RL, et al. Global Cancer Statistics 2020: GLOBOCAN Estimates of Incidence and Mortality Worldwide for 36 Cancers in 185 Countries. CA Cancer J Clin. 2021;71(3):209-49. doi: http://doi. org/10.3322/caac. 21660

23. Muzic JG, Schmitt AR, Wright AC, et al. Incidence and trends of basal cell carcinoma and cutaneous squamous cell carcinoma: a population-based study in olmsted county, Minnesota, 2000 to 2010. Mayo Clin Proc. 2017;92(6):890-8. doi: https://doi.org/10.1016/j. mayocp.2017.02.015

24. Curado MP, Hashibe M. Recent changes in the epidemiology of head and neck cancer. Curr Opin Oncol. 2009;21(3):194-200. doi: https://doi.org/10.1097/ CCO.0b013e32832a68ca
25. Mougeot JC, Stevens CB, Almon KG, et al. Cariesassociated oral microbiome in head and neck cancer radiation patients: a longitudinal study. J Oral Microbiol. 2019;11(1):1586421. doi: https://doi.org/10.1080/200 02297.2019 .1586421

26. Zhu XX, Yang XJ, Chao YL, et al. The potential effect of oral microbiota in the prediction of mucositis during radiotherapy for nasopharyngeal carcinoma. EBioMedicine. 2017;18:23-31. doi: https://doi. org/10.1016/j.ebiom.2017.02.002

27. Souza FRN, Meca LB, Correia ASC, et al. Microrganismos oportunistas na boca de pacientes irradiados: avaliação de 12 meses pós-tratamento. Arch Health Invest. 2015;4(5):55-61.

28. Vidal-Casariego A, Fernández-Natal I, Calleja-Fernández A, et al. Nutritional, microbiological, and therapeutic factors related to mucositis in head and neck cancer patients: a cohort study. Nutr Hosp. 2015;32(3):1208-13. doi: https://doi.org/10.3305/nh.2015.32.3.9299

29. Hu YJ, Shao ZY, Wang Q, et al. Exploring the dynamic core microbiome of plaque microbiota during head-andneck radiotherapy using pyrosequencing. PLoS One. 2013;8(2):e56343. doi: https://doi.org/10.1371/journal. pone. 0056343

30. Gaetti-Jardim Jr E, Ciesielski FIN, Nunes de Sousa FR, et al. Occurrence of yeasts, pseudomonads and enteric bacteria in the oral cavity of patients undergoing head and neck radiotherapy. Braz J Microbiol. 2011;42(3):1047-55. doi: https://doi.org/10.1590/ S1517-83822011000300024

31. Simóes CA, Castro JFL, Cazal C. Candida oral como fator agravante da mucosite radioinduzida. Rev Bras Cancerol. 2011;57(1):23-9. doi: https://doi.org/10.32635/21769745.RBC.2011v57n1.681

32. Dabas PS. An approach to etiology, diagnosis and management of different types of candidiasis. J Yeast Fungal Res. 2013;4(6):63-74. doi: https://doi. org/10.5897/JYFR2013.0113

33. Zhang J, Liu H, Liang X. et al. Investigation of salivary function and oral microbiota of radiation caries-free people with nasopharyngeal carcinoma. PLoS One. 2015;10(4):e0123137. doi: https://doi.org/10.1371/ journal.pone.0123137

Recebido em 9/3/2021 Aprovado em 5/7/2021 